\title{
Effect of probiotic and prebiotic fermented milk on skin and intestinal conditions in healthy young female students
}

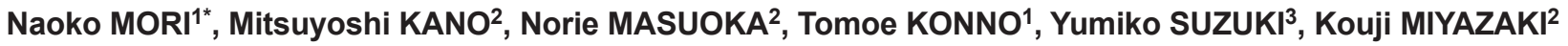 \\ and Yukihide UEKI ${ }^{1}$ \\ ${ }^{1}$ Department of Human Nutrition, Faculty of Human Nutrition, Seitoku University, 550 Iwase, Matsudo, Chiba 271-8555, Japan \\ 2 Yakult Central Institute, 5-11 Izumi, Kunitachi, Tokyo 186-8650, Japan \\ ${ }^{3}$ Chibaken Yakult Sales Corporation, 63 Kasoricho, Wakaba-ku, Chiba, Chiba 264-0017, Japan
}

Received October 1, 2015; Accepted March 2, 2016; Published online in J-STAGE April 1, 2016

\begin{abstract}
Although persistent constipation is considered to be associated with skin problems, the supporting evidence is limited. Hence, this study investigated the effects of probiotic and prebiotic fermented milk on skin and intestinal conditions in an open-label trial. Among the 101 Japanese healthy young female students that participated, the 81 subjects in the intake group consumed a bottle of probiotic and prebiotic fermented milk containing Bifidobacterium breve strain Yakult and galactooligosaccharides daily for 4 weeks after a pre-intake period of 4 weeks, while the 20 subjects in the non-intake group did not consume the test beverage. Defecation patterns, skin conditions including hydration levels in the stratum corneum, and urinary phenol and $p$-cresol levels were evaluated before (baseline) and after intake. All subjects completed the study. No differences in dietary intake and body mass index were observed between both groups during the trial. In the intake group, hydration levels of the stratum corneum, defecation frequency, and feces quantity significantly increased, and urinary phenol and p-cresol levels significantly decreased after intake compared with the corresponding baseline values. However, they did not significantly change in the non-intake group. A significant difference was observed between the intake group and non-intake group in regard to clearness of the skin as assessed by visual analogue scale. Therefore, consecutive intake of probiotic and prebiotic fermented milk might have beneficial effects on the skin that prevent dryness and beneficial effects on the intestinal conditions that stimulate defecation and decrease phenol production by gut bacteria in healthy young women.
\end{abstract}

Key words: phenols, probiotics, prebiotics, skin condition, Bifidobacterium, skin hydration, defecation

\section{INTRODUCTION}

Probiotics are defined as "live microorganisms, which when administered in adequate amounts, confer a health benefit on the host" [1, 2]. Among these probiotics, bifidobacteria and lactobacilli have been consumed as food, as they have traditionally been considered safe and beneficial for health and beauty. According to the 2006 WHO/FAO report, a recent scientific study suggested that probiotics play an important role in immunological, digestive, and respiratory functions [2]. Prebiotics such as galactooligosaccharides (GOS) are considered "food" for beneficial bacteria and are defined as "nondigestible food

\footnotetext{
*Corresponding author. Mailing address: Naoko Mori, Department of Human Nutrition, Faculty of Human Nutrition, Seitoku Univesrity, 550 Iwase, Matsudo, Chiba 271-8555, Japan. E-mail: nkawano@seitoku.ac.jp

C2016 BMFH Press

This is an open-access article distributed under the terms of the Creative Commons Attribution Non-Commercial No Derivatives (bync-nd) License $<$ http://creativecommons.org/licenses/by-nc-nd/4.0/>.
}

ingredients that beneficially affect the host by selectively stimulating the growth of one or a limited number of bacterial species in the colon, such as bifidobacteria and lactobacilli, which have the potential to improve host health" [3-7]. The combination of probiotics and prebiotics is called symbiotics, which show anti-infection properties and confer subsequent benefits on patients with abnormal intestinal microbiota, such as patients with severe surgical conditions or those with systemic inflammatory response syndrome [7-9].

The gut microbiota, which consists of approximately 100 trillion microorganisms belonging to several hundred species, is a complex ecosystem that allows for crosstalk between gut microorganisms and the host. The composition of the gut microbiota is generally stable among adults; however, a number of factors including peristalsis disorders, surgical operations of the stomach or small intestine, liver or kidney diseases, pernicious anemia, cancer, radiation or antibiotic therapies, immune disorders, emotional stress, poor diet, and ageing can change the balance of intestinal flora to tilt in the favor of 
harmful bacteria $[9,10]$.

Among Japanese women, there is a popular opinion that persistent constipation is associated with skin problems. Indeed, a questionnaire survey of 600 Japanese women found that women suffering from abnormal bowel movements tend to have subjective skin problems such as skin dryness $[11,12]$. Although a close association is known to exist between skin and intestinal conditions, scientific evidence supporting it is limited. Isawa et al. suggested that intake of yogurt improves skin conditions and constipation in women [13]. Iizuka et al. demonstrated that phenols (phenol and $p$-cresol) adversely affect in vitro keratinocyte differentiation and accumulate within murine skin; they also showed that intake of a prebiotic beverage not only reduced serum phenol levels but also improved skin conditions of female volunteers in an open clinical study $[14,15]$. Kano et al. reported that consecutive intake of fermented milk containing $B$. breve strain Yakult and GOS can decrease intestinal production of phenols, which are potentially harmful to the skin, and improve skin dryness in healthy adult women [16]. Thus, it is suggested that maintenance of a healthy gut environment by intake of probiotics and/or prebiotics induces not only a reduction of phenol production in the gut but also maintains good skin conditions [12]. It is well known that food components affect the colonic gut microbiota and the levels of various metabolites produced by intestinal microbes, such as phenols. In addition, it is generally recognized that lifestyle, dietary habits, ultraviolet radiation, and the enteral environment are factors influencing skin conditions in humans.

Thus, to further clarify the relationship between skin and intestinal conditions, we conducted a trial to verify whether consecutive intake of fermented milk containing a probiotic Bifidobacterium and a prebiotic GOS affected skin conditions, defecation patterns, and the production of phenols by gut microbiota in healthy young female subjects. Moreover, we discussed whether improvement of the gut environment beneficially affects skin health.

\section{MATERIALS AND METHODS}

\section{Subjects}

Eligible participants were counseled and enrolled into the study. This study was conducted according to the guidelines laid down in the Declaration of Helsinki, and all procedures involving human subjects were approved by the Human Studies Committee of Seitoku University, Matsudo, Chiba, Japan. Written informed consent was obtained from all subjects.

One hundred and one healthy female volunteers, aged 18-23 years, participated in the trial (Table 1). We excluded subjects who met our exclusion criteria, which included milk allergy or other food and skin allergies, pregnancy, lactation, attempting to become pregnant, mental and other diseases, taking medication that would affect bowel function or skin condition, and experience of severe bowel movement problems or persistent skin conditions for 1 month before and during the trial. During the trial, the subjects complied with dietary restrictions to avoid the intake of fermented milks, yogurt, lactic acid bacteria beverages, and pro- and prebiotic products other than the test beverage. However, cheese, pickles, and pasteurized foods were allowed.

\section{Test beverage}

The test beverage was a fermented milk containing GOS, polydextrose, B. breve strain Yakult (YIT 12272), Lactococcus lactis YIT 2027, and Streptococcus thermophilus YIT 2021. These bacteria were obtained from the Culture Collection Research Laboratory of Yakult Central Institute, Kunitachi, Tokyo, Japan (Table 2). During the trial, the test beverage had $>1 \times 10^{10}$ and $>1 \times 10^{10}$ colony forming units (cfu) per $100 \mathrm{ml}$ of $B$. breve and other lactic acid bacteria, respectively.

\section{Trial design}

The trial was carried out in Chiba, Japan, from October to December 2010, a period in which the temperature and humidity gradually decrease in the environment. The trial was composed of a pre-intake period that lasted 4 weeks and an intake period that lasted 4 weeks, considering both cycles of menstruation and epidermal turnover. The subjects were randomly divided into an intake group and non-intake group in the final week of the pre-intake period. The randomization was performed using the RAND function in Microsoft Excel. Sample size was not calculated, but $20 \%$ of the participants were assigned to the non-intake group, which did not drink the test drink. During the intake period, the 81 subjects in the test group consumed a bottle of the test beverage $(100 \mathrm{ml})$ every day after breakfast, while the 20 subjects in the nonintake group did not consume the test beverage during the same period.

Age, weight, height, body mass index (BMI), hydration level of the stratum corneum, and frequencies of skipping of meals and defecation were determined in the first week of the pre-intake period as background data to randomly divide the subjects into the 2 groups. The physical characteristics of the subjects and information regarding their food intake are shown in Table 3. 
Table 1. Background data of the subjects enrolled in the study

\begin{tabular}{|c|c|c|c|c|}
\hline Parameter & & & $\begin{array}{c}\text { Number of } \\
\text { subjects }(n=101)\end{array}$ & $\%$ \\
\hline \multirow[t]{3}{*}{ Smoking habit } & & Yes & 1 & 1.0 \\
\hline & & No & 98 & 97.0 \\
\hline & & No answer & 2 & 2.0 \\
\hline \multirow[t]{7}{*}{ Skipped meals/week } & & 0 & 68 & 67.3 \\
\hline & & 1 & 15 & 14.9 \\
\hline & & 2 & 10 & 9.9 \\
\hline & & 3 & 5 & 5.0 \\
\hline & & 4 & 1 & 1.0 \\
\hline & & 5 & 1 & 1.0 \\
\hline & & 6 & 1 & 1.0 \\
\hline \multirow{5}{*}{$\begin{array}{l}\text { Skin condition } \\
\quad 0-10 \mathrm{~cm} \text { visual analogue scale (VAS) }\end{array}$} & $\mathrm{Bad}$ & $0-1$ & 7 & 6.9 \\
\hline & & $2-3$ & 20 & 19.8 \\
\hline & & $4-5$ & 47 & 46.5 \\
\hline & $\downarrow$ & $6-7$ & 15 & 14.9 \\
\hline & Good & $8-10$ & 12 & 11.9 \\
\hline \multirow{5}{*}{$\begin{array}{l}\text { Skin dryness } \\
0-10 \mathrm{~cm} \text { visual analogue scale (VAS) }\end{array}$} & Yes & $0-1$ & 16 & 15.8 \\
\hline & $\uparrow$ & $2-3$ & 27 & 26.7 \\
\hline & & $4-5$ & 30 & 29.7 \\
\hline & $\downarrow$ & $6-7$ & 11 & 10.9 \\
\hline & No & $8-10$ & 17 & 16.8 \\
\hline
\end{tabular}

Table 2. Nutritional data of the test beverage

\begin{tabular}{lc}
\hline \multicolumn{1}{c}{ Parameter } & per $100 \mathrm{ml}$ \\
\hline Energy (kcal) & 49 \\
Protein (g) & 3.2 \\
Fat (g) & 0.1 \\
Carbohydrates (g) & 10.6 \\
Galacto-oligosaccharide (g) & 1.0 \\
Polydextrose (g) & 2.5 \\
\hline
\end{tabular}

\section{Diary}

Defecation frequency, feces quantity, skipping of meals, sleep hours, and factors influencing defecation that warranted special mention were recorded in a diary every day for 8 weeks by the subjects themselves. The diaries were collected at the end of every week during the trial.

\section{Dietary assessment}

Dietary habits during the test period were surveyed using a validated brief self-administered diet history questionnaire (BDHQ; a 58-item fixed-portion-type

Table 3. Physical characteristics of the subjects and information regarding their food intake ${ }^{* 1}$

\begin{tabular}{lccc}
\hline \multirow{2}{*}{ Parameter } & \multicolumn{2}{c}{ Group } & \multirow{2}{*}{ p-value } \\
\cline { 2 - 3 } & Intake $(\mathrm{n}=81)$ & Non-intake $(\mathrm{n}=20)$ & \\
\hline Age (years) & $19.7 \pm 1.0$ & $19.6 \pm 1.0$ & 0.853 \\
Body weight $(\mathrm{kg})$ & $54.6 \pm 8.0$ & $55.9 \pm 6.9$ & 0.389 \\
Body height $(\mathrm{cm})$ & $157.1 \pm 5.5$ & $160.3 \pm 5.6$ & 0.036 \\
BMI $\left(\mathrm{kg} / \mathrm{m}^{2}\right)$ & $22.1 \pm 3.0$ & $21.8 \pm 2.5$ & 0.865 \\
\hline Energy $(\mathrm{kcal} /$ day) & $1,480 \pm 624$ & $1,230 \pm 401$ & 0.095 \\
Protein $(\mathrm{g} /$ day/1,000 kcal) & $35.8 \pm 7.1$ & $33.9 \pm 4.7$ & 0.265 \\
Fat $(\mathrm{g} /$ day/1,000 kcal) & $29.9 \pm 7.5$ & $28.8 \pm 8.1$ & 0.960 \\
Carbohydrates $(\mathrm{g} /$ day/1,000 kcal) & $60.5 \pm 28$ & $62.0 \pm 27.3$ & 0.833 \\
\hline
\end{tabular}

Values are expressed as the mean \pm standard deviation (unpaired t-test).

${ }^{*}$ No significant differences were observed in the estimates of energy-adjusted intakes of 42 selected nutrients (based on the nutrient density method) between the intake and non-intake groups. BMI: body mass index. 
questionnaire) developed for assessing Japanese diets [17].

\section{Skin score determined using a visual analogue scale (VAS)}

Skin conditions were evaluated using a self-evaluation questionnaire and were rated on a $10-\mathrm{cm}$ VAS. A high value (nearing 10) indicated a positive result. The items of the questionnaire were as follows: (1) condition of the skin across the whole face, (2) presence of wrinkles, (3) skin tension and elasticity, (4) color of the skin under the eyes, (5) dryness of the skin, (6) edema of the skin, (7) clearness of the skin, (8) presence of blemishes, (9) makeup application, (10) presence of facial pimples, (11) smoothness of the skin, and (12) presence of sebum and dirt around the nose.

\section{Evaluation of diary entries and questionnaires}

The collected diaries and questionnaires were checked by trained dietitians and staff at Seitoku University. When missing answers, errors, or both were found, the subjects were requested to complete the diary entry or answer the questions again.

\section{Measurement of hydration levels of the stratum corneum}

Makeup was removed with a designated cleansing cream, and the skin of the subjects was acclimatized for 30 min under standardized conditions (temperature 21.9 $\pm 0.7^{\circ} \mathrm{C}$, humidity $48.7 \pm 1.5 \%$ ). The hydration level of the stratum corneum on the cheek was measured based on capacitance by using a Corneometer ${ }^{\circledR}$ CM825 (Integral, Tokyo, Japan) [18]. Measurements were repeated five times on the same site, and the averaged value was used for statistical analysis.

\section{Collection of urine}

Early-morning urine was collected using URO CATCH II ${ }^{\circledR}$ (ATLETA Inc., Osaka, Japan) containing $0.5 \mathrm{mg}$ neomycin trisulfate salt hydrate (Sigma-Aldrich, St. Louis, MO, USA).

\section{Analysis of phenols}

Levels of phenols (phenol and $p$-cresol) in urine were analyzed by high-performance lipid chromatography (HPLC) according to a previously reported method [16]. In brief, a test sample, concentrated hydrochloride, and 4-chlorophenol (internal standard) were mixed and heated at $100^{\circ} \mathrm{C}$ for $60 \mathrm{~min}$ to hydrolyze the phenol conjugates. After cooling in an ice bath, ether was added to the mixture, and the mixture was then agitated on a vortex mixer. Then, the ether layer was taken, neutralized, and dried with an $\mathrm{N}_{2}$ purge. The residue was dissolved in ethyl acetate and filtered through a $0.45-\mu \mathrm{m}$ Ultrafree-MC filter unit (Millipore, Billerica, MA, USA). Phenols were quantified by an HPLC system (Alliance ${ }^{\circledR}$ 2695, Waters, Milford, MA, USA) equipped with an L-column ODS ${ }^{\circledR}$ (CERI, Tokyo, Japan; 4.6 mm (i.d.) $\times$ $150 \mathrm{~mm}$ (length) and $5 \mu \mathrm{m}$ particle size), eluted with $1 \%$ aqueous phosphoric acid solution: acetonitrile (80:20 $\mathrm{v} / \mathrm{v}$ ) at a flow rate of $1 \mathrm{ml} / \mathrm{min}$ at $40^{\circ} \mathrm{C}$, and monitored with a 474 fluorescence detector (Waters, Milford, MA, USA; excitation at $260 \mathrm{~nm}$ and emission at $305 \mathrm{~nm}$ ). Urine phenol levels were normalized to urine creatinine levels, determined with a creatinine test kit (Wako Pure Chemical Industries), and expressed as $\mu \mathrm{M}$ phenol per $\mathrm{mM}$ creatinine.

\section{Statistical analysis}

Data are expressed as means $\pm \mathrm{SD}$. All data were analyzed using the t-test, Wilcoxon signed-rank test, or Mann-Whitney U test. Correlations among defecation frequency, feces quantity, urinary phenol levels, and skin moisture in the test periods were examined by Spearman correlation test. Two-sided p-values below 0.05 were considered to indicate statistical significance. SPSS Ver.11.5 and PASW Statistics Base Ver.18 (SPSS Japan Inc., Tokyo, Japan) were used to perform analyses.

\section{RESULTS}

\section{Subjects}

All 101 subjects completed the trial. Physical characteristics of the subjects and background data are summarized in Table 3. No differences in dietary intake, age, weight, height, and BMI were observed between the intake and non-intake groups during the trial. The adherence rate for the test drink in the intake period was $98.6 \%$.

\section{Food intake}

No significant differences were observed in the estimates of energy-adjusted intakes of 42 selected nutrients including dietary fiber (based on the nutrient density method) between the pre-intake and intake periods and between the groups (data not shown).

\section{Skin conditions determined using the VAS}

Skin conditions, determined using the VAS, are shown in Table 4. Skin conditions across the whole face, clearness of skin, and the presence of sebum and dirt around the nose increased significantly from $4.4 \pm 2.1$ to $5.1 \pm 2.2,4.2 \pm 2.2$ to $4.8 \pm 2.6$, and $2.9 \pm 2.4$ to $3.4 \pm$ 
Table 4. VAS of the skin parameters

\begin{tabular}{|c|c|c|c|c|c|}
\hline \multirow[b]{2}{*}{ Parameter } & \multirow[b]{2}{*}{ Group } & \multirow[b]{2}{*}{ (1) Before intake } & \multirow[b]{2}{*}{ (2) After intake } & \multicolumn{2}{|c|}{ p-value } \\
\hline & & & & (1) vs (2) & $\begin{array}{l}\text { Amount of } \\
\text { change* }^{* 1}\end{array}$ \\
\hline \multirow[t]{2}{*}{ Condition of the skin across the whole face } & Intake & $4.4 \pm 2.1$ & $5.1 \pm 2.2$ & $0.001 * *$ & 0.160 \\
\hline & Non-intake & $4.1 \pm 2.6$ & $4.3 \pm 2.5$ & 0.974 & \\
\hline \multirow[t]{2}{*}{ Presence of wrinkles } & Intake & $6.8 \pm 2.6$ & $6.1 \pm 3.0$ & $0.009 * *$ & 0.622 \\
\hline & Non-intake & $6.2 \pm 3.5$ & $5.4 \pm 2.9$ & 0.145 & \\
\hline \multirow[t]{2}{*}{ Skin tension and elasticity } & Intake & $5.4 \pm 2.3$ & $5.8 \pm 2.4$ & 0.228 & 0.684 \\
\hline & Non-intake & $4.9 \pm 2.1$ & $4.9 \pm 2.1$ & 0.808 & \\
\hline \multirow[t]{2}{*}{ Color of the skin under the eyes } & Intake & $4.7 \pm 2.9$ & $4.6 \pm 2.9$ & 0.787 & 0.399 \\
\hline & Non-intake & $3.9 \pm 2.9$ & $4.4 \pm 3.0$ & 0.289 & \\
\hline \multirow[t]{2}{*}{ Dryness of the skin } & Intake & $4.1 \pm 2.8$ & $4.2 \pm 2.7$ & 0.829 & 0.952 \\
\hline & Non-intake & $3.2 \pm 3.0$ & $3.2 \pm 2.7$ & 0.825 & \\
\hline \multirow[t]{2}{*}{ Edema of the skin } & Intake & $5.1 \pm 2.7$ & $5.2 \pm 2.7$ & 0.701 & 0.476 \\
\hline & Non-intake & $4.7 \pm 2.7$ & $5.1 \pm 2.7$ & 0.494 & \\
\hline \multirow[t]{2}{*}{ Clearness of the skin } & Intake & $4.2 \pm 2.2$ & $4.8 \pm 2.6$ & $0.008 * *$ & $0.024^{*}$ \\
\hline & Non-intake & $4.5 \pm 2.0$ & $3.9 \pm 1.8$ & 0.230 & \\
\hline \multirow[t]{2}{*}{ Presence of blemishes } & Intake & $4.4 \pm 2.8$ & $4.2 \pm 2.9$ & 0.799 & 0.823 \\
\hline & Non-intake & $4.4 \pm 2.8$ & $4.4 \pm 2.7$ & 0.886 & \\
\hline \multirow[t]{2}{*}{ Makeup application } & Intake & $4.7 \pm 2.4$ & $4.8 \pm 2.4$ & 0.518 & 0.111 \\
\hline & Non-intake & $4.0 \pm 2.3$ & $3.4 \pm 2.1$ & $0.033^{*}$ & \\
\hline \multirow[t]{2}{*}{ Presence of facial pimples } & Intake & $4.6 \pm 2.8$ & $4.9 \pm 2.9$ & 0.205 & 0.281 \\
\hline & Non-intake & $4.3 \pm 3.1$ & $4.2 \pm 3.4$ & 0.850 & \\
\hline \multirow[t]{2}{*}{ Smoothness of the skin } & Intake & $4.8 \pm 2.5$ & $5.0 \pm 2.6$ & 0.280 & 0.733 \\
\hline & Non-intake & $4.3 \pm 1.9$ & $4.5 \pm 2.1$ & 0.639 & \\
\hline \multirow[t]{2}{*}{ Presence of sebum and dirt around the nose } & Intake & $2.9 \pm 2.4$ & $3.4 \pm 2.5$ & $0.014 *$ & 0.197 \\
\hline & Non-intake & $3.1 \pm 2.5$ & $2.8 \pm 2.3$ & 0.749 & \\
\hline
\end{tabular}

Intake, $\mathrm{n}=81$; non-intake, $\mathrm{n}=20$. Values are expressed as the mean \pm standard deviation of each group. ${ }^{*} \mathrm{p}<0.05,{ }^{*} \mathrm{p}<0.01$ (Wilcoxon signed-rank test or Mann-Whitney U test).

A high value (nearing 10) indicated positive result.

${ }^{* 1}$ Intake group (after-before) vs. non-intake group (after-before).

2.5 , respectively, after intake in the intake group ( $\mathrm{p}<0.01$, $\mathrm{p}<0.01$ and $\mathrm{p}<0.05$, respectively). However, the presence of wrinkles decreased significantly from $6.8 \pm 2.6$ to $6.1 \pm$ 3.0 after intake in the intake group $(\mathrm{p}<0.01)$. In contrast, makeup application decreased significantly from $4.0 \pm$ 2.3 to $3.4 \pm 2.1$ in only the non-intake group ( $<<0.05$ ). A significant difference was observed between the intake group and non-intake group in regard to clearness of the skin.

\section{Defecation patterns}

Table 5 shows changes in the parameters of defecation before and after intake. In the intake group, the defecation frequency, stool consistency, and feces quantity were significantly increased after the intake period compared with the corresponding values at baseline. They did not change in the non-intake group.
Levels of hydration in the stratum corneum and urinary phenol levels

Table 5 also shows changes in hydration levels in the stratum corneum and urinary phenol levels. The hydration level of the stratum corneum significantly increased in the intake group after the intake period compared with that observed at baseline. Moreover, urinary $p$-cresol and phenol levels significantly decreased. In contrast, the levels did not change in the non-intake group during the same period. However, there was no correlation (using the Spearman test) among phenols, skin data, and defecation data.

\section{DISCUSSION}

The skin represents the primary interface between the human host and the environment. B. breve strain Yakult 
Table 5. Defecation frequency, feces quantity, urinary phenol levels, and skin moisture in the test periods

\begin{tabular}{llccc}
\hline \multicolumn{1}{c}{ Parameter } & \multicolumn{1}{c}{ Group } & Before intake & After intake & p-value \\
\hline (1) Defecation frequency & Intake & $4.5 \pm 1.5$ & $4.9 \pm 1.6$ & $<0.001^{* * *}$ \\
(days/week) & Non-intake & $4.7 \pm 1.3$ & $4.5 \pm 1.5$ & 0.424 \\
(2) Feces quantity & Intake & $2.4 \pm 1.5$ & $2.7 \pm 1.6$ & $0.004^{* *}$ \\
$\quad$ Units ${ }^{*} /$ week) & Non-intake & $2.3 \pm 1.5$ & $2.3 \pm 1.5$ & 1.000 \\
(3) Urinary p-cresol & Intake & $32.6 \pm 33.4$ & $23.6 \pm 24.5$ & $0.030^{*}$ \\
$(\mu \mathrm{M} / \mathrm{mM}$ CRE) & Non-intake & $29.3 \pm 32.9$ & $18.0 \pm 20.1$ & 0.192 \\
(4) Urinary phenol & Intake & $16.4 \pm 11.1$ & $11.4 \pm 9.6$ & $0.000^{* * *}$ \\
$\quad(\mu \mathrm{M} / \mathrm{mM}$ CRE) & Non-intake & $15.5 \pm 11.3$ & $10.5 \pm 6.3$ & 0.072 \\
(5) Hydration level of the stratum corneum & Intake & $23.2 \pm 8.2$ & $25.1 \pm 9.2$ & $0.029^{*}$ \\
$(\mathrm{AU})$ & Non-intake & $24.5 \pm 13.8$ & $24.1 \pm 10.2$ & 0.881 \\
\hline
\end{tabular}

Intake, $\mathrm{n}=81$; non-intake, $\mathrm{n}=20$. Values are expressed as the mean \pm standard deviation of each group. $* \mathrm{p}<0.05$; $* * \mathrm{p}<0.01 ; * * * \mathrm{p}<0.001$ ((1 and 2) Wilcoxon signed-rank test, (3-5) paired t-test).

${ }^{*}$ A fecal model with a 4-cm diameter and a ping-pong ball-like shape was considered 1 unit.

and GOS, a typical probiotic and prebiotic, respectively, are beneficial, as they improve intestinal environments by reducing toxic phenol production by the gut bacteria [18-20] and production via other mechanisms. Based on previous studies, we conducted an open-label study to verify whether consecutive intake of fermented milk containing a probiotic $B$. breve strain Yakult and the prebiotic GOS affects skin conditions, defecation patterns, and the production of phenols by gut microbiota in healthy young women.

Diet and the composition of resident microbial populations in the gut are dynamic factors influencing the skin condition. It has been proved that probiotics have the ability to restrain the population of harmful intestinal bacteria and improve skin condition [11-16]. However, the influence of a participant's meal was not considered in almost all of these previous studies. In this study, a difference in food intake was not observed between the intake and non-intake groups, except for consumption of the test beverage. Therefore, it was judged that intake of the test beverage directly influenced the difference in results obtained from the two groups.

Available amino acids produced during the digestion of proteins and peptides by several proteases are converted by microbes in the colon into various metabolites, including ammonia amines, indoles, and thiols, resulting in undesirable effects on the host [21]. In particular, the aromatic amino acid L-tyrosine is metabolized into phenols such as phenol and $p$-cresol by gut bacteria such as Escherichia coli, Proteus species, Bacteroides fragilis, and Clostridium species [22]. The phenols thus produced are regarded as bioactive toxins and biomarkers of a disturbed gut environment. Although a certain amount of phenols is excreted into the feces, a substantial amount is absorbed rapidly by the colon, conjugated to sulfate in the liver and colonic mucosa, and subsequently circulated through the bloodstream, before ultimately being excreted through the urine [21]. These phenols cause skin problems by disrupting keratinization [15].

Previous studies found that levels of phenolic metabolites are influenced by the frequency and condition of bowel movements [18-21, 23]; thus, the increase in defecation frequency observed in this study may have led to a reduction in the proportion of phenol-producing bacteria. The relationships between the colonic microbiota, their metabolic products, and the host immune system are crucial to the maintenance of intestinal homeostasis and are important to the functions of the skin. It is suggested that improvement of the intestinal microbiota by consuming pre-and probiotics contributed to the reduction in urinary phenol levels; however, we have not yet examined intestinal environments extensively, apart from the phenolic metabolites.

The clearness of the skin improved in the intake group compared with the non-intake group. These results may be related to improved defecation frequency, decreased phenol levels, and increased hydration of the stratum corneum. Decreased phenol levels and increased skin hydration levels were previously shown by Kano et al. [16]; however, defecation frequency was not analyzed in their study. Thus, the simultaneous improvement in four markers observed in this study is a new finding.

\section{LIMITATIONS}

A sufficient number of control subjects and a placebo condition were not included because this was a pilot study. 
This study was conducted during the autumn and winter months. It is well known that skin moisture is affected by seasonal changes in the environment [24]; hence, it is unclear whether the results obtained in this study will be reproducibly obtained in experiments conducted in other seasons. In addition, the subjects in this study were healthy young women; hence, a further experiment is needed to investigate whether similar results will be obtained in subjects with dry skin and constipation. Although the increase in skin moisture observed in the test group might be related to a decrease in the phenol levels of the feces, the underlying mechanism was not clearly elucidated. In addition, to ensure the validity of the analysis in a study, regression toward the mean must be considered when designing the study. However, our study did not include a placebo group as a control group.

\section{CONCLUSION}

Based on results of this study, regular intake of fermented milk is expected to help maintain healthy skin by increasing defecation frequency, stool consistency, and feces quantity in healthy young women. However, further study is required to clarify the detailed mechanism underlying the effects of fermented milk on skin health and the relationship between the intestinal environment and skin condition.

\section{ACKNOWLEDGEMENTS}

We thank Dr. Kenshi Okubo for providing technical help and valuable discussions. We also thank the staff of the Yakult Central Institute and the Faculty of Research and Development of Yakult Honsha for manufacturing the test beverages.

\section{REFERENCES}

1. Fuller R. 1989. Probiotics in man and animals. J Appl Bacteriol 66: 365-378. [Medline] [CrossRef]

2. FAO/WHO Guidelines for the Evaluation of Probiotics in Food 2002, Working Group on Drafting Guidelines for the Evaluation of Probiotics in Food. (section 5.3, Expert report, at ftp://ftp.fao.org/es/esn/food/Reid.pdf.

3. Tanaka R, Takayama H, Morotomi M, Kuroshima T, Ueyama S, Matsumoto K, Kuroda A, Mutai M. 1983. Effects of administration of TOS and Bifidobacterium breve 4006 on the human fecal flora. Bifidobacteria Microflora 2: 17-24. [CrossRef]

4. Ito M, Deguchi Y, Miyamori A, Matsumoto K, Kikuchi H, Matsumoto K, Kobayashi Y, Yajima T, Kan T. 1990. Effects of administration of galactooligosaccharides on the human faecal microflora, stool weight andabdominal sensation. Microb Ecol Health Dis 3:
285-292. [CrossRef]

5. Gibson GR, Roberfroid MB. 1995. Dietary modulation of the human colonic microbiota: introducing the concept of prebiotics. J Nutr 125: 1401-1412. [Medline]

6. Guarner F, Malagelada JR. 2003. Gut flora in health and disease. Lancet 361: 512-519. [Medline] [CrossRef]

7. Shioiri T, Yahagi K, Nakayama S, Asahara T, Yuki N, Kawakami K, Yamaoka Y, Sakai Y, Nomoto K, Totani M. 2006. The effects of a symbiotic fermented milk beverage containing Lactobacillus casei strain Shirota and transgalactosylated oligosaccharides on defecation frequency, intestinal microflora, organic acid concentrations, and putrefactive metabolites of sub-optimal health state volunteers: a randomized placebo-controlled cross-over study. Biosci Microflora 25: 137-146. [CrossRef]

8. Miyazaki K, Matsuzaki T. 2008. Health properties of milk fermented with Lactobacillus casei strain Sirota (LcS). In Handbook of Fermented Functional Foods, 2nd ed, Edward RF (ed), CRC Press, Boca Raton, pp.165-208.

9. Mitsuoka T. 1996. Intestinal flora and human health. Asia Pac J Clin Nutr 5: 2-9. [Medline]

10. Ley RE, Turnbaugh PJ, Klein S, Gordon JI. 2006. Microbial ecology: human gut microbes associated with obesity. Nature 444: 1022-1023. [Medline] [CrossRef]

11. Masuoka N. 2012. Probiotics and prebiotics improve gut environment and skin condition. Cosmetic Stage 7: 20-25 (in Japanese).

12. Miyazaki K, Masuoka N, Kano M, Iizuka R. 2014. Bifidobacterium fermented milk and galactooligosaccharides lead to improved skin health by decreasing phenols production by gut microbiota. Benef Microbes 5: 121-128 [CrossRef] [Medline]

13. Isawa $K$, Noma $T$, Yamamoto $M$, Kimura $K$, Ito H, Taketomo N, Numano K, Kawashima M. 2008. Verifying the ability of yogurt prepared with LB81 lactic acid bacteria to improve skin function. J Intestinal Microbiol 22: 1-5 (in Japanese).

14. Iizuka R, Kawakami K, Izawa N, Chiba K. 2009. Phenols produced by gut bacteria affect the skin in hairless mice. Microb Ecol Health Dis 21: 50-56. [CrossRef]

15. Iizuka R, Kawakami K, Chiba K. 2009. Gut bacteria producing phenols disturb keratinocyte differentiation in human skin. Microb Ecol Health Dis 21: 221-227. [CrossRef]

16. Kano M, Masuoka N, Kaga C, Sugimoto S, Iizuka R, Manabe K, Sone T, Oeda K, Nonaka C, Miyazaki K, Ishikawa F. 2013. Consecutive intake of fermented milk containing Bifidobacterium breve strain Yakult and galactooligosaccharides benefits skin condition in healthy adult women. Biosci Microbiota Food Health 32: 33-39. [Medline] [CrossRef] 
17. Kobayashi S, Murakami K, Sasaki S, Okubo H, Hirota N, Notsu A, Fukui M, Date C. 2011. Comparison of relative validity of food group intakes estimated by comprehensive and brief-type self-administered diet history questionnaires against $16 \mathrm{~d}$ dietary records in Japanese adults. Public Health Nutr 14: 1200-1211. [Medline] [CrossRef]

18. Smith EA, Macfarlane GT. 1996. Enumeration of human colonic bacteria producing phenolic and indolic compounds: effects of $\mathrm{pH}$, carbohydrate availability and retention time on dissimilatory aromatic amino acid metabolism. J Appl Bacteriol 81: 288-302. [Medline] [CrossRef]

19. Matsumoto K, Deguchi Y, Takada T, Iino T, Osada K, Haga K, Hirano K, Nomoto K, Ishikawa F, Watanuki M, Iino H. 2001. Effects of intake of beverage containing galactooligosaccharides and polydextrose on defecation and fecal microflora. J Nutr Food 3: $1-13$.

20. Matsumoto K, Takada T, Yuki N, Kawakami K, Sakai T, Nomoto K, Kimura K, Matsumoto K, Iino H. 2004.
Effect of transgalactosylated oligosaccharides mixture (N-GOS) in human intestinal microflora. J Intestinal Microbiol 18: 25-35.

21. de Loor H, Bammens B, Evenepoel P, De Preter V, Verbeke K. 2005. Gas chromatographic-mass spectrometric analysis for measurement of p-cresol and its conjugated metabolites in uremic and normal serum. Clin Chem 51: 1535-1538. [Medline] [CrossRef]

22. Berardesca E, Borroni G. 1995. Instrumental evaluation of cutaneous hydration. Clin Dermatol 13: 323-327. [Medline] [CrossRef]

23. Kawano N, Konno T, Suzuki Y, Kawai M, Takada T, Setoyama H, Ikemura H, Ueki Y. 2012. The effect of fermented milk on constipation-prone individuals classified according to the stress level. Jpn J Nutri Dietetics 70: 3-16 (in Japanese). [CrossRef]

24. Sone T, Ichioka M, Yokokura T. 1991. A study of seasonal changes in skin surface configuration and rough skin by image analysis. J Jpn Cosmet Sci Soc 15: 60-65. 